Article

\title{
Investigation on the Correlation between Dispersion Characteristics at Terahertz Range and Dielectric Permittivity at Low Frequency of Epoxy Resin Nanocomposites
}

\author{
Ze Lian ${ }^{1,2, * \mathbb{D} \text {, Danyang Chen }}{ }^{1}$ and Shengtao $\mathrm{Li}^{2}$ \\ 1 State Grid Shanxi Electric Power Research Institute, Taiyuan 030001, China; cdydanyangchen@hotmail.com \\ 2 State Key Laboratory of Electrical Insulation and Power Equipment, Xi'an Jiaotong University, \\ Xi'an 710049, China; sli@mail.xjtu.edu.cn \\ * Correspondence: lznewman@stu.xjtu.edu.cn or lznewman@foxmail.com; Tel.: +86-15333662660
}

Citation: Lian, Z.; Chen, D.; Li, S Investigation on the Correlation between Dispersion Characteristics at Terahertz Range and Dielectric Permittivity at Low Frequency of Epoxy Resin Nanocomposites. Polymers 2022, 14, 827. https:/ / doi.org/10.3390/polym14040827

Academic Editor: Dan Rosu

Received: 25 January 2022

Accepted: 18 February 2022

Published: 21 February 2022

Publisher's Note: MDPI stays neutral with regard to jurisdictional claims in published maps and institutional affiliations.

Copyright: (C) 2022 by the authors. Licensee MDPI, Basel, Switzerland. This article is an open access article distributed under the terms and conditions of the Creative Commons Attribution (CC BY) license (https:// creativecommons.org/licenses/by/ $4.0 /)$

\begin{abstract}
Despite the extensive research on nanocomposites, a fundamental theory on the interface region is still difficult to achieve. In the present paper, we chose epoxy resin and nano- $\mathrm{SiO}_{2}$, nano-SiC, nano- $\mathrm{ZnO}$ to prepare three kinds of nanocomposites. The dispersion characteristics at the terahertz range and dielectric permittivity at $1 \mathrm{~Hz}$ of epoxy resin-based nanocomposites were investigated. The reduction of the permittivity of nanocomposites at a slight filler concentration was absent at the terahertz range. The measurement results at $1 \mathrm{~Hz}$ show that the interaction between nano-SiO${ }_{2}$, nano-SiC particles and epoxy resin was strong with the modification of the silane coupling agent. However, the modification of nano-ZnO particles was invalid. The Lorentz harmonic oscillator model was employed to fit the dispersion characteristics. The relevance between the damping constant and the dielectric permittivity at low frequency was established, indicating that the increase in the damping coefficient results from the restriction of the molecular chain motion by the interfacial region. The present results in this paper reveal a bright prospect of terahertz time-domain spectroscopy in establishing the theory of nanocomposite dielectric.
\end{abstract}

Keywords: epoxy resin; nanocomposites; terahertz time-domain spectroscopy; Lorentz oscillator model; dispersion characteristics

\section{Introduction}

Since the concept of "nanodielectrics" was first introduced in 1994 by Lewis, it has attracted much attention due to its superior properties and excellent prospect in the electric industry [1-3]. Various enhanced properties of nanocomposites, such as electric strength, mechanical strength, space charge accumulation, and so on, were reported by researchers [4-7]. Nowadays, it has been generally accepted that most of the superior properties can be attributed to the interface region [8,9]. Although several models were proposed to interpret the superior properties [2,10-12], it is still difficult to accomplish a fundamental understanding of the interaction between nanoparticles and poly matrices $[8,13]$.

With the addition of a nano-filler, the molecular motion of polymer is suppressed by the interface region, resulting in the relaxation processes at different frequency ranges exhibiting different changes with the electric field [14]. However, the relationship between the dielectric properties and the microstructure has not been established [9]. According to the proposed models, the thickness of the interface region is estimated to be about tens to hundreds of nanometers, depending on filler type, filler size, and the interaction between the nano-filler and the polymer matrix [11]. Due to the characteristic frequency of this space scale being located in the high-frequency region, the dispersion characteristics at the highfrequency region may provide a glimpse of the change in microstructure. The terahertz spectrum includes phonon vibration, small molecule rotation, hydrogen bond stretching torsion, and chemical bond low-frequency vibration, which cannot be characterized by 
a broadband dielectric spectrum at low frequency [15]. Significant progress has been achieved in investigating the molecular dynamics of polymers in the terahertz band [16-20]. The coherent detection mode of the terahertz time-domain spectroscopy (THz-TDS) makes it convenient to obtain the dispersion characteristics of testing materials at the terahertz range [21-25]. The investigation of the dispersion characteristics of nanocomposites is beneficial to the exploiting of fundamental theory in nanocomposites [26-30].

Among the polymer matrices that constitute nanocomposites, epoxy resin is one of the most popular materials for insulating systems [31,32]. It is widely used in drytype transformers, generator stators, bushing, cable termination, and so on [33,34]. The epoxy resin-based nanocomposites, which were expected to be the next generation of dielectric materials, have attracted much attention in recent years [35]. In this paper, we employed epoxy resin as a polymer matrix and three kinds of nano-fillers to constitute nanocomposites. The THz-TDS was employed to study the dispersion characteristics of epoxy resin-based nanocomposites. The dielectric constant at low frequency $(1 \mathrm{~Hz}$ in this paper) was obtained too. The correlation of dispersion characteristics at the terahertz range and dielectric constant at low frequency was discussed.

\section{Materials and Methods}

\subsection{Fabrication of Epoxy Resin Nanocomposites}

In the present study, we chose bisphenol-A epoxy resin (E51) and methyl tetrahydrophthalic anhydride hardener as matrix and curing agent, respectively. The curing agent was used at 80 phr. DMP30 was chosen as the accelerant which was used at 1 phr. Three kinds of epoxy/nanocomposites were prepared with the addition of nano- $\mathrm{SiO}_{2}$ particles, nano-SiC particles and nano-ZnO particles with average diameter of $40 \mathrm{~nm}$. These nanomaterials in this paper are commercial nanomaterials (Hangzhou Wanjing New Material Co., LTD, Hangzhou, China). The silane coupling agent (KH550) was used to ensure the dispersity of nanoparticles in epoxy resin matrix.

The fabrication process of epoxy resin nanocomposites was shown in Figure 1. During the fabrication process, we employed a shearing instrument IKA-T25 with a maximum speed of r/min (Shanghai Yikong Electromechanical Co., LTD, Shanghai, China) and an ultrasonic device KQ-100KDE (Kunshan Ultrasonic Instrument Co., LTD, Kunshan, China), which operates at a frequency of $40 \mathrm{kHz}$ and a power of $99 \mathrm{~W}$. The $\mathrm{KH}-550$ and cyclohexane were mixed by ultrasonic dispersion. Then the nanoparticles were added to the mixture (solution 1). Both high-speed shearing and ultrasonic dispersion were applied on solution 1 to avoid the agglomeration of nanoparticles. After the mixture of epoxy resin, high-speed shearing was employed again. Then, the curing agent and the accelerant DMP30 were added to the mixture. The obtained mixture was stirring at in vacuum for $1 \mathrm{~h}$ at $60^{\circ} \mathrm{C}$. Then, to accomplish the curing process, the mixture was poured into the mold and placed into the oven at $85^{\circ} \mathrm{C}$ for $2 \mathrm{~h}, 105^{\circ} \mathrm{C}$ for $2 \mathrm{~h}$, and $120^{\circ} \mathrm{C}$ for $10 \mathrm{~h}$, respectively. When the samples were cooled, the polishing, cleaning, and drying were carried out before the measurements. The arrangement of nanocomposites samples was listed in Table 1. It is generally accepted that the amount of nano-filler is lower than $10 \%$. Therefore, we chose five kinds of filler content to constitute nanocomposites in the present paper, as listed in Table 1 . The thickness of each sample was kept at about $1 \mathrm{~mm}$.

Table 1. Arrangement of nanocomposite samples.

\begin{tabular}{ccc}
\hline Sample & Component & Filler content \\
\hline $\mathrm{EP} / \mathrm{SiO}_{2}$ & Epoxy resin $+40 \mathrm{~nm} \mathrm{SiO} 2$ & $0 \%, 1 \%, 3 \%, 5 \%, 7 \%, 10 \%$ \\
$\mathrm{EP} / \mathrm{SiC}$ & Epoxy resin $+40 \mathrm{~nm} \mathrm{SiC}$ & $0 \%, 1 \%, 3 \%, 5 \%, 7 \%, 10 \%$ \\
$\mathrm{EP} / \mathrm{ZnO}$ & Epoxy resin $+40 \mathrm{~nm} \mathrm{ZnO}$ & $0 \%, 1 \%, 3 \%, 5 \%, 7 \%, 10 \%$ \\
\hline
\end{tabular}




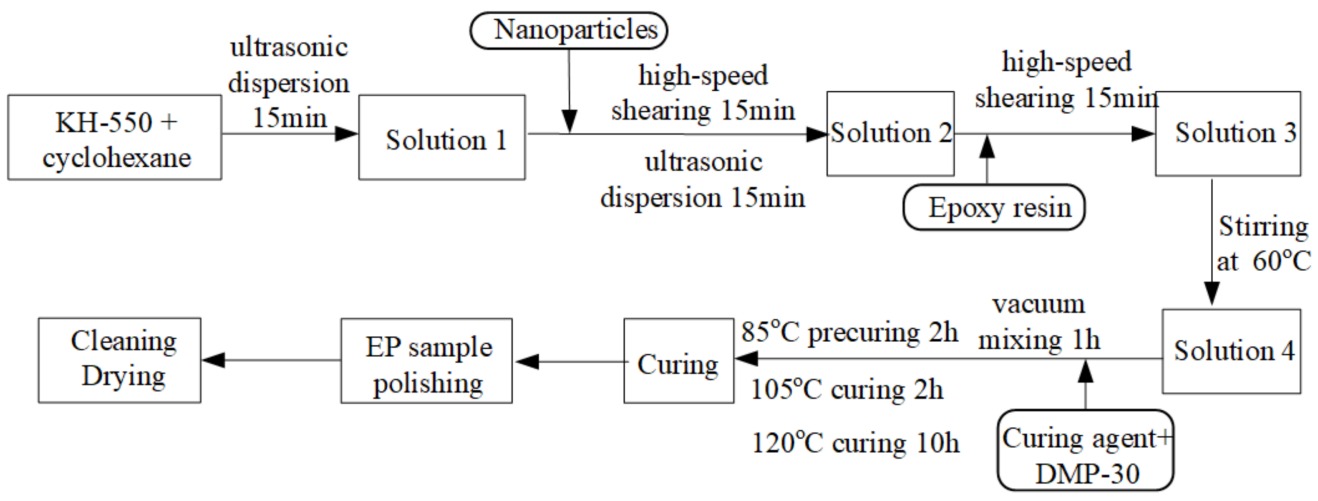

Figure 1. Sample preparation process of nanocomposites.

\subsection{Terahertz Time-Domain Spectroscopy System}

A CIP-TDS terahertz time-domain spectroscopy system (DaHeng Technology Co., LTD, Beijing, China) of was employed to investigate the dispersion characteristics of nanocomposites at terahertz range. The terahertz time-domain spectroscopy system was shown in Figure 2. In the present paper, the experiments were carried out in transmission mode. As shown in Figure 2, it is mainly composed of femtosecond laser, terahertz radiation generation device, terahertz detection system, time delay control system and various lenses. In the present CIP-TDS systems, the femtosecond laser was emitted by a model-locked Ti:sapphire laser. The pulse width, wavelength and repetition rate of the laser were $80 \mathrm{fs,}$ $800 \mathrm{~nm}$ and $80 \mathrm{MHz}$, respectively. The laser was split into two beams: one for pump of terahertz emission and the other for the detection of terahertz radiation [36]. In this study, the low temperature-grown GaAs photoconductive antennas and ZnTe crystal were employed for the emitter and detector of terahertz radiation, respectively. The system achieves a peak dynamic range of $60 \mathrm{~dB}$ and a bandwidth of $3.5 \mathrm{THz}$. In order to avoid the strong absorption effect of water vapor on terahertz waves, dry nitrogen was continuously introduced into the cavity to keep the relative humidity below 3\% [37]. After obtaining the time-domain spectrum of the sample, the frequency domain spectrum was obtained by fast Fourier transform, and the dielectric constant and dielectric loss were calculated by using the refractive index and extinction coefficient in the transmission function [22]. Each sample was tested three times and the average value was taken as the final result.

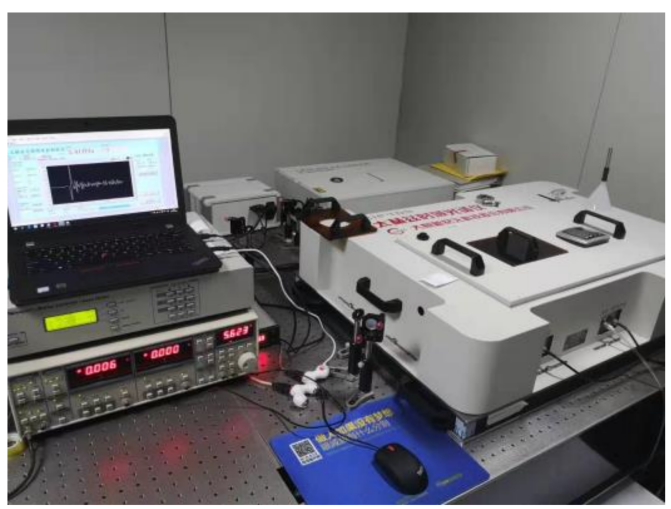

Figure 2. The CIP-TDS system employed in present paper.

In addition, in order to have a comparison with the dielectric properties at low frequency, we employed a Novocontrol broadband dielectric spectrometer to measure the dielectric constant at $1 \mathrm{~Hz}$. 


\subsection{Methods}

In the THz-TDS measurements, the reference signals and the sample signals in timedomain were measured, respectively. Then the fast Fourier transform was performed to obtain the $E_{r e f}(v)$ and $E_{s}(v)$ in frequency domain [37]. The transmission function of sample for terahertz wave can be expressed as follows:

$$
H(v)=\frac{E_{\mathrm{S}}(v)}{E_{r e f}(v)}=\rho(v) e^{-i \Delta \phi(v)}
$$

As described in the literature, we can acquire the refractive index and extinction coefficient of sample by the following equations [38,39]:

$$
\begin{gathered}
n_{s}(v)=1+\frac{c \varphi(v)}{v d} \\
\kappa_{S}(v)=\left\{\ln \left[\frac{4 n_{s}(v)}{\left(n_{s}(v)+1\right)^{2}}\right]-\ln \rho(v)\right\} \frac{c}{v d}
\end{gathered}
$$

where $c$ is the speed of light in vacuum and $d$ is the thickness of the sample. According to the generalized Maxwell relation between the complex permittivity and the complex refractive index, the real and imaginary parts of the permittivity are obtained:

$$
\begin{gathered}
\varepsilon \prime(v)=\left[n_{s}(v)\right]^{2}-\left[\kappa_{s}(v)\right]^{2} \\
\varepsilon^{\prime \prime}(v)=2 n_{s}(v) \kappa_{s}(v)
\end{gathered}
$$

The dispersion characteristics of epoxy resin nanocomposites in the terahertz range can be well described by the Lorentz oscillator model [40,41]:

$$
\varepsilon^{*}(v)=\varepsilon_{\infty}+\frac{\Omega^{2}}{\left(v_{0}^{2}-v^{2}\right)-\mathrm{i} \gamma v}
$$

where $\varepsilon_{\infty}$ is the dielectric constant in the infinite frequency, $\Omega, v_{0}$ and $\gamma$ are respectively the oscillator strength, the resonance frequency and the damping constant of the resonant mode.

\section{Results}

Figure 3a shows the measured signals of $\mathrm{EP} / \mathrm{SiO}_{2}$ nanocomposites in the time domain. Compared with the reference signal, the signals changed markedly because of the interaction between the terahertz radiation and the samples. Moreover, the waveforms nanocomposites reach a maximum later than that of the epoxy resin. The corresponding amplitude spectra in the frequency range are given in Figure $3 \mathrm{~b}$. With the filler content increasing, the amplitude of the nanocomposites decreased slightly.

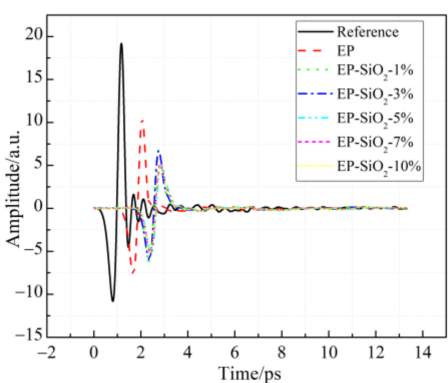

(a)

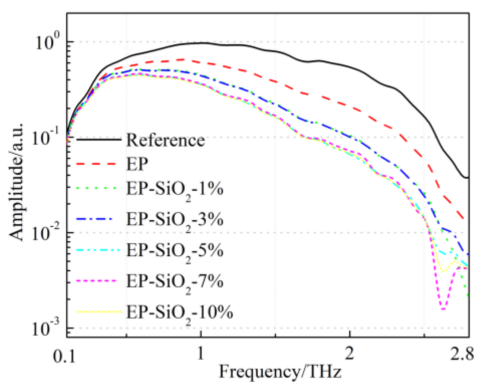

(b)

Figure 3. THz time-domain spectra and amplitude spectra of the reference and the $\mathrm{EP} / \mathrm{SiO}_{2}$ nanocomposites: (a) Terahertz waves of reference and $\mathrm{EP} / \mathrm{SiO}_{2}$ samples in time domain; (b) The corresponding spectra in frequency domain. 
According to the above formulas in Section 2.3, we can acquire the dielectric permittivity of the $\mathrm{EP} / \mathrm{SiO}_{2}$ nanocomposites. Figure 4 exhibits the frequency dependence of the real and imaginary part dielectric function of the $\mathrm{EP} / \mathrm{SiO}_{2}$ nanocomposites. As shown in Figure $4 \mathrm{a}$, the dielectric permittivity of all samples decreases monotonically with an increasing frequency. In addition, at a certain frequency, the $\varepsilon^{\prime}$ of $\mathrm{EP} / \mathrm{SiO}_{2}$ nanocomposites gets higher when increasing the filler content. The imaginary part of the dielectric function is illustrated in Figure $4 b$. The results indicate that the $\varepsilon^{\prime \prime}$ of $\mathrm{EP} / \mathrm{SiO}_{2}$ nanocomposites has no evident changes when filler content is lower than $3 \%$. When the filler content is higher than $5 \%$, the $\varepsilon^{\prime \prime}$ of nanocomposites becomes larger than the EP.

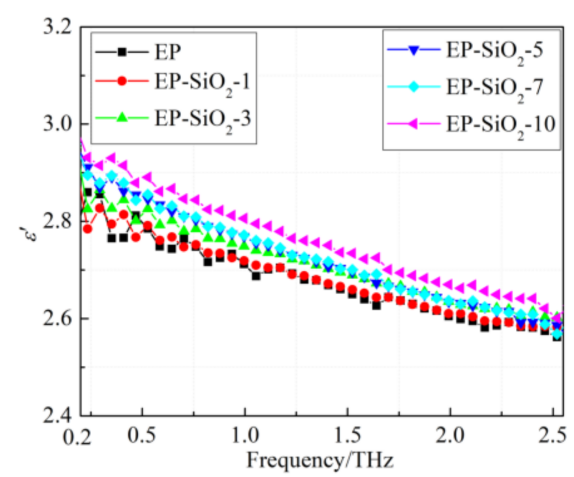

(a)

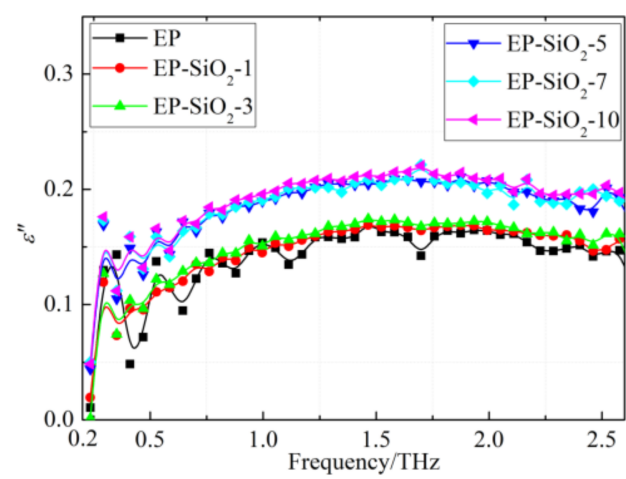

(b)

Figure 4. Frequency dependence of real and imaginary part of dielectric function of $\mathrm{EP} / \mathrm{SiO}_{2}$ nanocomposites: (a) Real part; (b) Imaginary part.

The same measurements were carried out on the $\mathrm{EP} / \mathrm{SiC}$ nanocomposite. Figure 5 exhibits the waveforms of the reference and the $\mathrm{EP} / \mathrm{SiC}$ nanocomposites in the time domain and the corresponding spectra in the frequency domain. Similarly, a distinct change can be observed in Figure 5a. The time delay of the maximum in the signals of the $\mathrm{EP} / \mathrm{SiC}$ nanocomposites is bigger than that of the $\mathrm{EP} / \mathrm{SiO}_{2}$ nanocomposites, which may result from a higher dielectric constant. Accordingly, the amplitude spectra show a monotonically decreasing relationship with respect to the filler content.

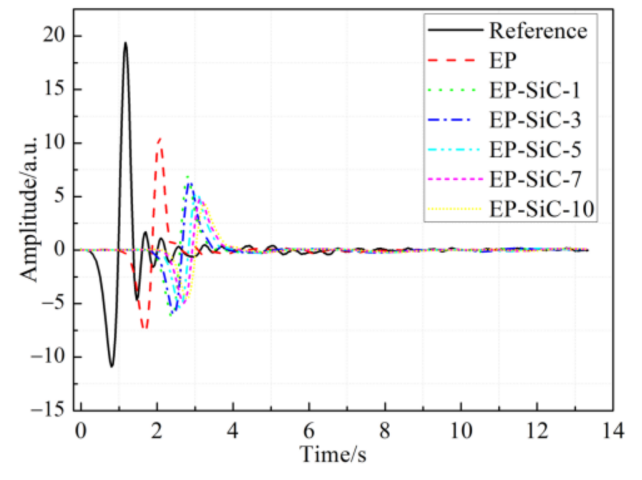

(a)

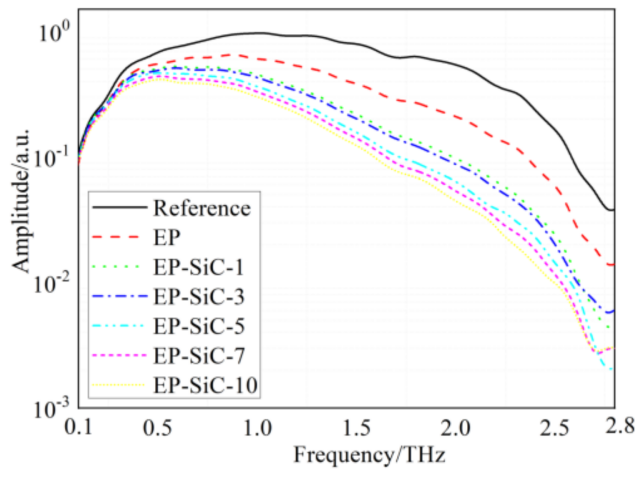

(b)

Figure 5. THz time-domain spectra and amplitude spectra of the reference and the $\mathrm{EP} / \mathrm{SiC}$ nanocomposites: (a) Terahertz waves of reference and $\mathrm{EP} / \mathrm{SiC}$ samples in time domain; (b) The corresponding spectra in frequency domain.

Figure 6 illustrates the calculated dielectric permittivity of the EP/SiC nanocomposites. Figure 6a shows the frequency dependence of the real part of dielectric function in the $0.2-2.8 \mathrm{THz}$ range. No peak was observed on the curves of the dielectric function. It is apparent that the $\varepsilon^{\prime}$ of all the $\mathrm{EP} / \mathrm{SiC}$ samples decreases monotonously with the increase 
in frequency. However, with the filler content increasing, the increase in the $\mathrm{EP} / \mathrm{SiC}$ nanocomposites is more significant than that of the $\mathrm{EP} / \mathrm{SiO}_{2}$ nanocomposites. As shown in Figure $6 \mathrm{~b}$, the $\varepsilon^{\prime \prime}$ of the $\mathrm{tEP} / \mathrm{SiC}$ nanocomposites increases with the increasing filler content, which is different from the situation in the $\mathrm{EP} / \mathrm{SiO}_{2}$ nanocomposites.

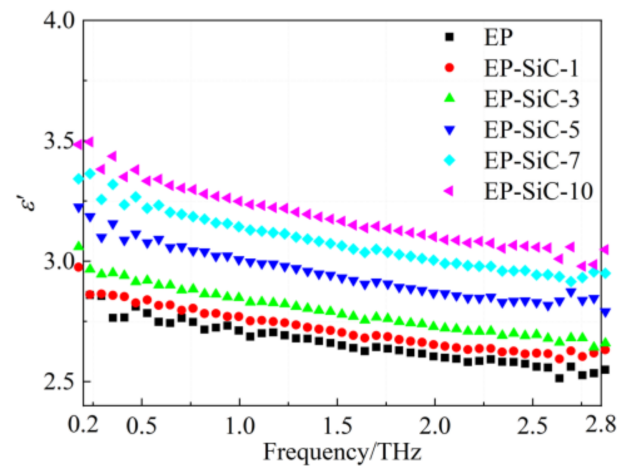

(a)

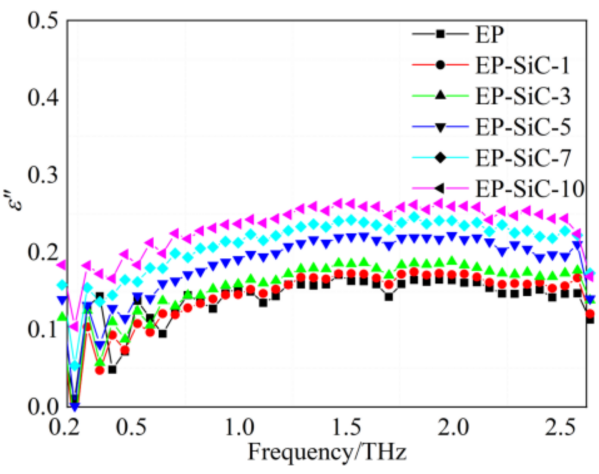

(b)

Figure 6. Frequency dependence of real and imaginary part of dielectric function of EP/SiC nanocomposites: (a) Real part; (b) Imaginary part.

Figure 7 shows the $\mathrm{THz}$ time-domain waveforms and amplitude spectra of the reference and the EP/ZnO nanocomposites. The curves in Figure 7a exhibit similar characteristics compared to the results of the $\mathrm{EP} / \mathrm{SiO}_{2}$ nanocomposites. Likewise, there is no peak appearing in the corresponding amplitude spectra, as demonstrated in Figure $7 \mathrm{~b}$.

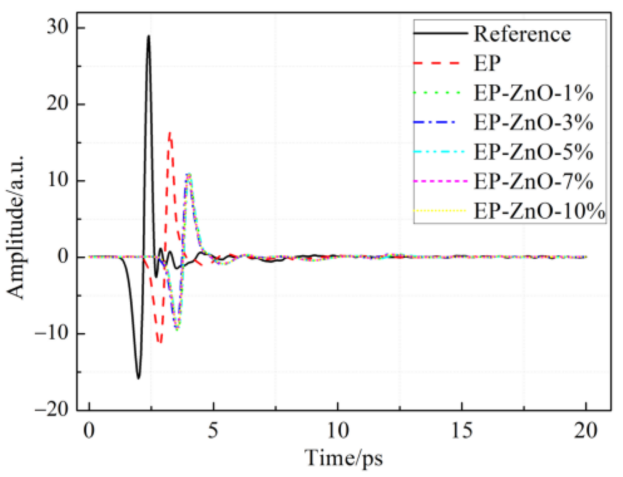

(a)

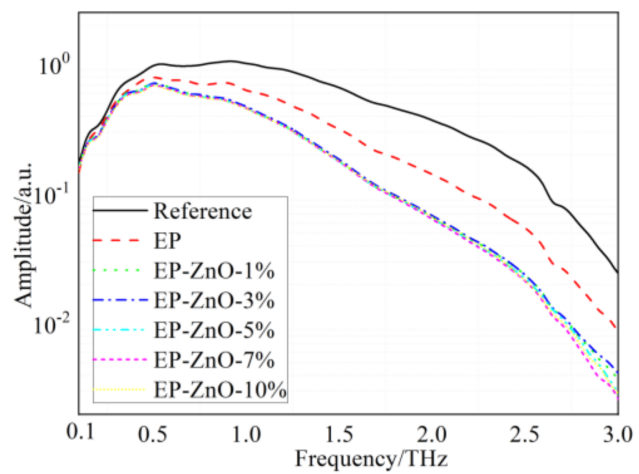

(b)

Figure 7. THz time-domain spectra and amplitude spectra of the reference and the EP/ ZnO nanocomposites: (a) Terahertz waves of reference and EP/ZnO samples in time domain; (b) The corresponding spectra in frequency domain.

Similar to the two types of nanocomposites above, we can obtain the frequency dependence of the real and imaginary part of the dielectric function of the EP/ZnO nanocomposites, as shown in Figure 8. As demonstrated in Figure 8a, the addition of the nano- $\mathrm{ZnO}$ fillers makes a similar difference to the dielectric permittivity of the EP compared to the nano- $\mathrm{SiO}_{2}$ fillers. Nevertheless, the imaginary part of the dielectric permittivity of the $\mathrm{EP} / \mathrm{ZnO}$ nanocomposites, as shown in Figure $8 \mathrm{~b}$, differs from that of both the $\mathrm{EP} / \mathrm{SiO}_{2}$ and the EP/SiC nanocomposites. The curves shown in Figure $8 \mathrm{~b}$ overlap each other. It is difficult to tell them apart. These results imply that the three types of nano-fillers employed in this study have different effects on the dispersion characteristics of the epoxy resin. 


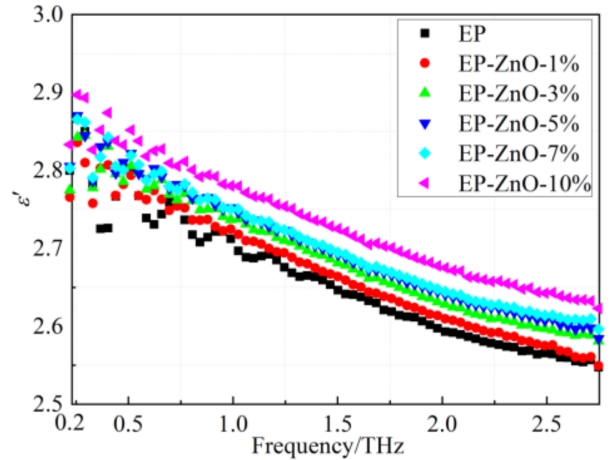

(a)

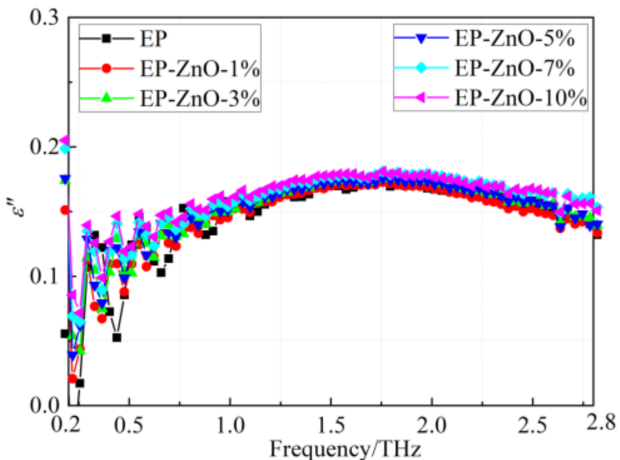

(b)

Figure 8. Frequency dependence of real and imaginary part of dielectric function of $\mathrm{EP} / \mathrm{ZnO}$ nanocomposites: (a) Real part; (b) Imaginary part.

\section{Discussion}

In this paper, we fitted the dielectric function of the EP nanocomposites by the Lorentz oscillator model with one vibrational mode, as given in Equation (6). For simplicity, we only exhibit the fitting curves of the $\mathrm{EP}-\mathrm{SiO}_{2}-1$ and the $\mathrm{EP}-\mathrm{SiO}_{2}-7$ in this paper. As shown in Figure 9, the dielectric function of the $\mathrm{EP} / \mathrm{SiO}_{2}$ nanocomposites can be well reproduced by the Lorentz oscillator model. For test results of both the EP-SiO -1 and the $\mathrm{EP}-\mathrm{SiO}_{2}-7$ samples, a confidence coefficient higher than 0.99 is acquired. The excellent agreement between the experimental data and fitting curves indicates that the dispersion characteristics of nanocomposites based on the epoxy resin in the $0.1-2.5 \mathrm{THz}$ are dominated by the resonant process. The dielectric functions of the $\mathrm{EP} / \mathrm{SiO}_{2}, \mathrm{EP} / \mathrm{SiC}$, and $\mathrm{EP} / \mathrm{ZnO}$ nanocomposites were fitted with the same process. The obtained fitting parameters are summarized in Table 2. For all fitting processes, the confidence coefficient is larger than 0.98.

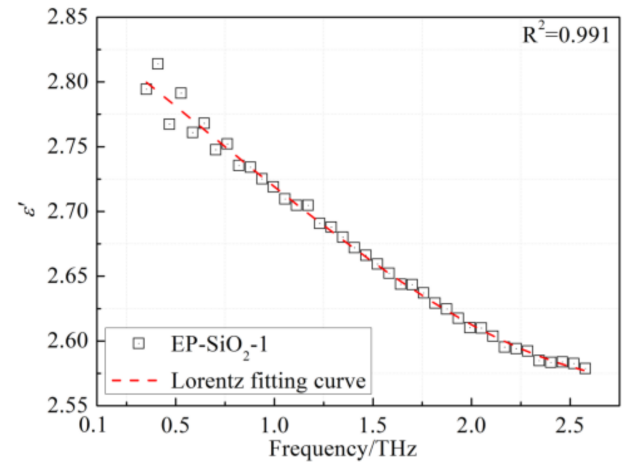

(a)

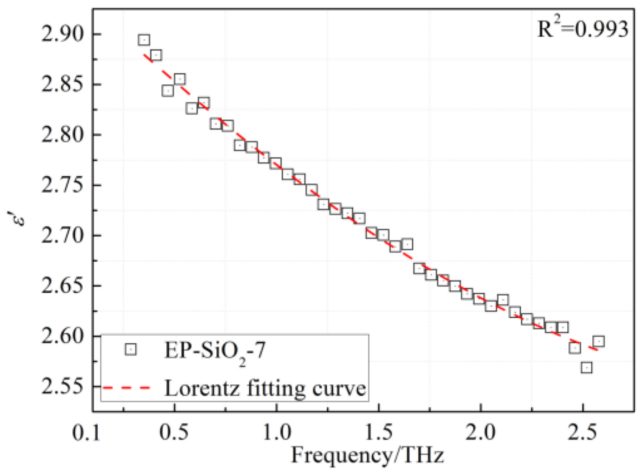

(b)

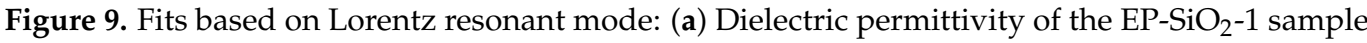
and the fitting curve with a confidence coefficient of 0.991 ; (b) Dielectric permittivity of the $\mathrm{EP}_{-} \mathrm{SiO}_{2}-7$ sample and the fitting curve with a confidence coefficient of 0.993 .

In order to have a more intuitive understanding of the effect of nanoparticles on dispersion characteristics, we draw the dielectric permittivity of nanocomposites with respect to filler content at an infinite frequency $\left(\varepsilon_{\infty}\right.$ in Table 2$)$ and at $1 \mathrm{THz}$ in Figure 10. As shown in Figure 10a, the dielectric permittivity at an infinite frequency increases with the introduction of nanofillers. At an infinite frequency, the effective medium theory is suitable to estimate the dielectric response of the composites. Therefore, the increase $\varepsilon_{\infty}$ of nanocomposites can be attributed to the fact that the nanofillers have higher dielectric permittivity than the epoxy resin matrix. The dielectric constant at a low frequency of $\mathrm{SiO}_{2}$, 
$\mathrm{ZnO}$ and $\mathrm{SiC}$ employed in this paper is 3.9,4.5, and 9.8, respectively. Consequently, at the same filler content, the $\mathrm{EP} / \mathrm{SiC}$ sample owns the highest dielectric permittivity and the $\mathrm{EP} / \mathrm{SiO}_{2}$ owns the lowest.

Table 2. Lorentz fitting parameters for the dielectric functions of nanocomposites.

\begin{tabular}{ccccc}
\hline Composites & $\varepsilon_{\infty}$ & $\omega_{0} / \mathbf{2} \boldsymbol{\pi} \mathbf{( T H z )}$ & $\Omega / 2 \pi(\mathbf{T H z})$ & $\gamma(\mathbf{T H z})$ \\
\hline $\mathrm{EP}$ & 2.448 & 1.732 & 1.41 & 2.67 \\
$\mathrm{EP} / \mathrm{SiO}_{2}-1$ & 2.475 & 1.828 & 1.85 & 2.81 \\
$\mathrm{EP} / \mathrm{SiO}_{2}-3$ & 2.477 & 1.774 & 1.79 & 3.13 \\
$\mathrm{EP} / \mathrm{SiO}_{2}-5$ & 2.489 & 1.721 & 1.42 & 2.96 \\
$\mathrm{EP} / \mathrm{SiO}_{2}-7$ & 2.497 & 1.692 & 1.26 & 2.52 \\
$\mathrm{EP} / \mathrm{SiO}_{2}-10$ & 2.508 & 1.671 & 1.09 & 2.14 \\
$\mathrm{EP} / \mathrm{SiC}-1$ & 2.517 & 1.829 & 2.17 & 3.45 \\
$\mathrm{EP} / \mathrm{SiC}-3$ & 2.596 & 1.796 & 2.09 & 3.27 \\
$\mathrm{EP} / \mathrm{SiC}-5$ & 2.736 & 1.744 & 1.55 & 2.51 \\
$\mathrm{EP} / \mathrm{SiC}-7$ & 2.847 & 1.742 & 1.34 & 2.34 \\
$\mathrm{EP} / \mathrm{SiC}-10$ & 2.949 & 1.689 & 1.21 & 2.23 \\
$\mathrm{EP} / \mathrm{ZnO}-1$ & 2.462 & 1.772 & 1.24 & 2.45 \\
$\mathrm{EP} / \mathrm{ZnO}-3$ & 2.503 & 1.771 & 1.16 & 2.26 \\
$\mathrm{EP} / \mathrm{ZnO}-5$ & 2.549 & 1.783 & 1.04 & 1.21 \\
$\mathrm{EP} / \mathrm{ZnO}-7$ & 2.568 & 1.787 & 0.63 & 1.18 \\
$\mathrm{EP} / \mathrm{ZnO}-10$ & 2.586 & 1.792 & 0.35 &
\end{tabular}

Figure $10 \mathrm{~b}$ shows the dielectric permittivity of nanocomposites at $1 \mathrm{THz}$. Likewise, the $\varepsilon^{\prime}$ increases with the increasing filler content. The experimental phenomenon that dielectric permittivity at low frequencies decreases with the introduction of nanofillers were not observed. We reported similar results in a previous study [26]. In addition, the vibration and rotation of molecular groups are unable to keep up with the electromagnetic field, resulting in the dielectric permittivity at infinite frequency being slightly lower than that at $1 \mathrm{THz}$.

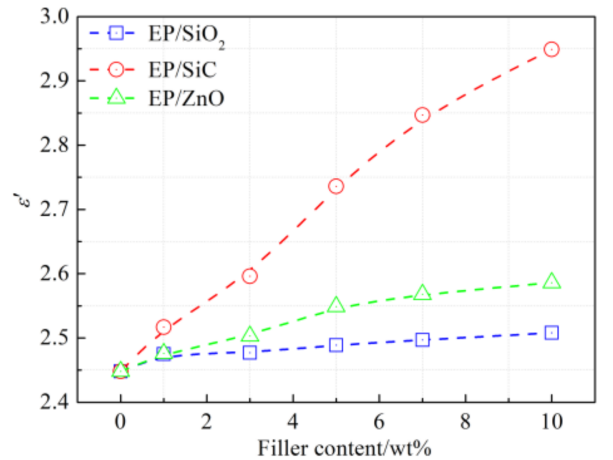

(a)

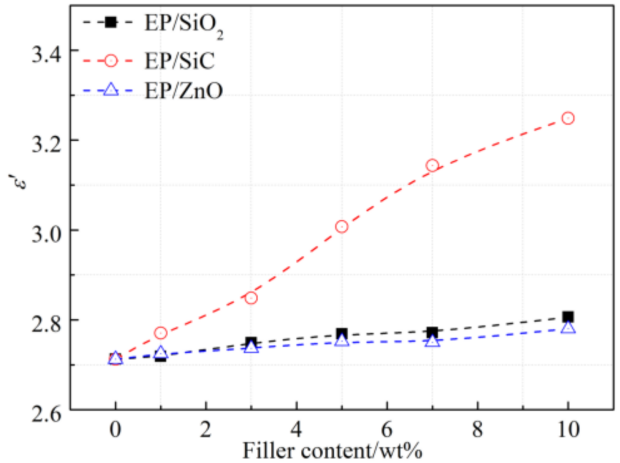

(b)

Figure 10. The dielectric permittivity for three types of nanocomposites with respect to filler content: (a) At infinite frequency; (b) At $1 \mathrm{THz}$.

The absence of the feature that dielectric permittivity of nanocomposites decreases after introducing nanofillers leads us to wonder whether there is a nano-structure formed between the nanofillers and the epoxy resin matrix in the composites studied in the present paper. We measured the dielectric permittivity at $1 \mathrm{~Hz}$ for the three types of nanocomposites, as shown in Figure 11. The results indicate that the dielectric permittivity of $\mathrm{EP} / \mathrm{SiO}_{2}$ and $\mathrm{EP} / \mathrm{SiC}$ decreases firstly and then it increases with the increasing filler content. The $\varepsilon^{\prime}$ of the $\mathrm{EP} / \mathrm{SiC}$ achieves the minimum value at a filler content of $1 \%$, while $\varepsilon^{\prime}$ of the $\mathrm{EP} / \mathrm{SiO}_{2}$ achieves the minimum at $3 \%$. However, the dielectric permittivity at $1 \mathrm{~Hz}$ of the $\mathrm{EP} / \mathrm{ZnO}$ in the present study increases monotonously with the increasing filler content. In general, the 
reduction of dielectric permittivity was attributed to the suppression of molecular motion by the addition of nanofillers.

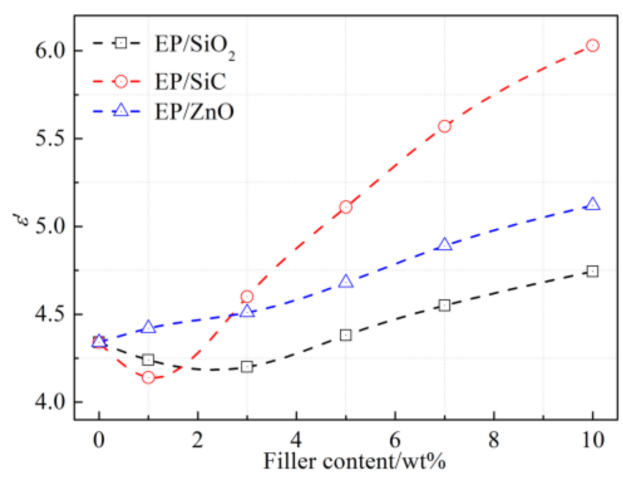

Figure 11. The dielectric permittivity at $1 \mathrm{~Hz}$ for three types of nanocomposites with respect to filler content.

According to our previous work [26], the dielectric permittivity of the epoxy resin at the $10^{-1}$ to $10^{3} \mathrm{~Hz}$ frequency range is dominated by the $\alpha$-process, which is affected significantly by the interface region. The stronger the interaction between the nanofillers and epoxy resin is, the more effective the suppression of molecular motion works. Therefore, we can speculate that the interaction strength of the interface region in each nanocomposite is different. The surface of the nano- $\mathrm{SiO}_{2}$ and the nano-SiC were modified successfully, leading to the strong interaction between the polymer matrix and these nanoparticles. However, the modification of the silane coupling agent used in this study is invalid for nano- $\mathrm{ZnO}$ particles, resulting in the fact that the alignment layer did not appear in $\mathrm{EP} / \mathrm{ZnO}$ nanocomposites.

Due to that the $\gamma$ representing the damping constant of the resonant mode, which can characterize the strength of molecular motion, we draw the fitted damping constant (as listed in Table 2) of the nanocomposites with respect to the filler content in Figure 12. As shown in Figure 12, the damping coefficients of $\mathrm{EP} / \mathrm{SiO}_{2}$ and $\mathrm{EP} / \mathrm{SiC}$ increase firstly and then decrease with the increase in filler content, which exhibits a converse trend with the dielectric constant at $1 \mathrm{~Hz}$. When the filler content is greater than $7 \%$, the $\gamma$ of the nanocomposite is lower than that of the unfilled epoxy resin. This result indicates that the agglomeration of nanoparticles occurred in the nanocomposites with high filler content. Moreover, the $\gamma$ of $\mathrm{EP} / \mathrm{SiO}_{2}$ and $\mathrm{EP} / \mathrm{SiC}$ reach their maximum at the filler content of $3 \%$ and $1 \%$, respectively, which is identical with the filler content that they achieve their minimum permittivity.

As for $\mathrm{EP} / \mathrm{ZnO}$, the damping coefficient decreases monotonously with increasing filler content. This result implies that the introduction of nano- $\mathrm{ZnO}$ in the present study loosens the molecular motion of the epoxy resin matrix. Consequently, no decline appeared in the $\varepsilon^{\prime}$ of the $\mathrm{EP} / \mathrm{ZnO}$ composites, as shown in Figure 11. The progressive increase with increasing filler content is mainly caused by the introduction of the $\mathrm{ZnO}$ particle, which owns a higher dielectric permittivity than the epoxy resin matrix and the loose structure resulting from the agglomeration of nanoparticles.

Moreover, the results in Figure 12 indicate that the silane coupling agent KH550 improves the good adhesion between nano- $\mathrm{SiO}_{2}$ particles, nano-SiC particles, and the epoxy matrix, resulting in the motions of polymer main chains being restrained significantly. However, the improvement is absent in the EP/ZnO nanocomposites. Due to the strong relevance between the dielectric permittivity at $1 \mathrm{~Hz}$ and the damping constant, we can deduce that the damping constant of dispersion characteristics at the terahertz range can effectively describe the strength of molecular motion which contributes greatly to the dielectric permittivity at low frequencies. The bigger the damping constant is, the stronger the interaction between the nanofillers and the polymer matrix is. Hence, the study of 
dispersion characteristics at the terahertz range may provide valuable information for the fundamental understanding of interface regions in nanocomposites.

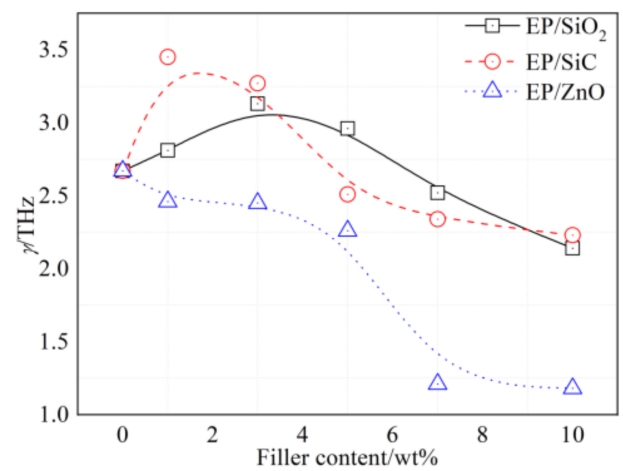

Figure 12. The damping constant for three types of nanocomposites versus filler content.

\section{Conclusions}

In this paper, we prepared three kinds of nanocomposites with different filler contents based on epoxy resin. The dispersion characteristics at the terahertz range of the nanocomposites were investigated with THz-TDS. We can draw the following conclusions:

(1) The addition of nano- $\mathrm{SiO}_{2}$ and nano-SiC have an obvious influence on the dispersion characteristics of the epoxy resin, while the addition of nano-ZnO does not make any difference. The employment of the silane coupling agent KH550 did not establish a strong interaction between the nano- $\mathrm{ZnO}$ particles and the epoxy resin matrix.

(2) The permittivity of the nanocomposites at $1 \mathrm{THz}$ increases monotonously with the increase in nanoparticle content. Whereas the permittivity of the nanocomposites at $1 \mathrm{~Hz}$ shows different variation rules. The molecular motion of epoxy resin was suppressed by the addition of nano- $\mathrm{SiO}_{2}$ and nano-SiC with slight filler content.

(3) The dielectric function of nanocomposites at the terahertz range can be well reproduced by the Lorentz oscillator model. The fitted damping coefficient of nanocomposites with respect to filler content shows a converse trend to which the permittivity at $1 \mathrm{~Hz}$ varies with filler content.

(4) A strong relevance between the dielectric permittivity at low frequency and the damping constant was discovered in the present paper. These results show that THz-TDS is very promising in the study of the interface region and the fundamental understanding of nanocomposites.

Author Contributions: All authors have contributed to the writing of this manuscript. Samples preparation, measurement, data processing, interpretation of the results, writing the manuscript, Z.L.; Writing the manuscript, D.C.; Theory and methodology, S.L. All authors have read and agreed to the published version of the manuscript.

Funding: This research received no external funding.

Institutional Review Board Statement: Not applicable.

Informed Consent Statement: Not applicable.

Data Availability Statement: The data presented in this study are available on request from the corresponding author.

Conflicts of Interest: The authors declare no conflict of interest.

\section{References}

1. Lewis, T.J. Nanometric Dielectrics. IEEE Trans. Dielectr. Electr. Insul. 1994, 1, 812-825. [CrossRef]

2. Nelson, J.K.; IEEE. The Promise of Dielectric Nanocomposites. In Proceedings of the Conference Record of the 2006 IEEE International Symposium on Electrical Insulation, Toronto, ON, Canada, 11-14 June 2006; pp. 452-457. 
3. Siddabattuni, S.; Schuman, T.P.; Dogan, F. Dielectric Properties of Polymer-Particle Nanocomposites Influenced by Electronic Nature of Filler Surfaces. ACS Appl. Mater. Interfaces 2013, 5, 1917-1927. [CrossRef]

4. Li, S.; Xie, D.; Lei, Q. Understanding Insulation Failure of Nanodielectrics: Tailoring Carrier Energy. High Volt. 2020, 5, 643-649. [CrossRef]

5. Wang, W.W.; Min, D.M.; Li, S.T. Understanding the Conduction and Breakdown Properties of Polyethylene Nanodielectrics: Effect of deep traps. IEEE Trans. Dielectr. Electr. Insul. 2016, 23, 564-572. [CrossRef]

6. Ullah, M.; Kausar, A.; Siddiq, M.; Subhan, M.; Zia, M.A. Reinforcing Effects of Modified Nanodiamonds on the Physical Properties of Polymer-Based Nanocomposites: A Review. Polym.-Plast. Technol. Eng. 2015, 54, 861-879. [CrossRef]

7. Ju, S.T.; Zhang, H.; Chen, M.J.; Zhang, C.; Chen, X.; Zhang, Z. Improved electrical insulating properties of LDPE based nanocomposite: Effect of surface modification of magnesia nanoparticles. Compos. Part A-Appl. Sci. Manuf. 2014, 66, 183-192. [CrossRef]

8. Pleşa, I.; Noţingher, P.V.; Schlögl, S.; Sumereder, C.; Muhr, M. Properties of Polymer Composites Used in High-Voltage Applications. Polymers 2016, 8, 173. [CrossRef] [PubMed]

9. Pourrahimi, A.M.; Olsson, R.T.; Hedenqvist, M.S. The Role of Interfaces in Polyethylene/Metal-Oxide Nanocomposites for Ultrahigh-Voltage Insulating Materials. Adv. Mater. 2018, 30, 1703624. [CrossRef] [PubMed]

10. Schadler, L. Nanocomposites-Model interfaces. Nat. Mater. 2007, 6, 257-258. [CrossRef]

11. Tanaka, T.; Kozako, M.; Fuse, N.; Ohki, Y. Proposal of a multi-core model for polymer nanocomposite dielectrics. IEEE Trans. Dielectr. Electr. Insul. 2005, 12, 669-681. [CrossRef]

12. Shengtao, L.; Guilai, Y.; Suna, B.; Jianying, L. A new potential barrier model in epoxy resin nanodielectrics. IEEE Trans. Dielectr. Electr. Insul. 2011, 18, 1535-1543.

13. Yang, W.H.; Yi, R.; Hui, S.S.; Xu, Y.; Cao, X.L. Analysis of the Dielectric Spectroscopy of an Epoxy-ZnO Nanocomposite Using the Universal Relaxation Law. J. Appl. Polym. Sci. 2013, 127, 3891-3897. [CrossRef]

14. Shengtao, L.; Guilai, Y.; Chen, G.; Jianying, L.; Suna, B.; Lisheng, Z.; Yunxa, Z.; Qingquan, L. Short-term breakdown and long-term failure in nanodielectrics: A review. IEEE Trans. Dielectr. Electr. Insul. 2010, 17, 1523-1535.

15. Parrott, E.P.J.; Zeitler, J.A. Terahertz Time-Domain and Low-Frequency Raman Spectroscopy of Organic Materials. Appl. Spectrosc. 2015, 69, 1-25. [CrossRef] [PubMed]

16. Zeranska-Chudek, K.; Lapinska, A.; Siemion, A.; Jastrzebska, A.M.; Zdrojek, M. Terahertz time domain spectroscopy of graphene andMXenepolymer composites. J. Appl. Polym. Sci. 2021, 138, 49962. [CrossRef]

17. Jepsen, P.U.; Cooke, D.G.; Koch, M. Terahertz spectroscopy and imaging-Modern techniques and applications. Laser Photon. Rev. 2011, 5, 124-166. [CrossRef]

18. Baxter, J.B.; Guglietta, G.W. Terahertz Spectroscopy. Anal. Chem. 2011, 83, 4342-4368. [CrossRef] [PubMed]

19. Dhillon, S.S.; Vitiello, M.S.; Linfield, E.H.; Davies, A.G.; Hoffmann, M.C.; Booske, J.; Paoloni, C.; Gensch, M.; Weightman, P.; Williams, G.P.; et al. The 2017 terahertz science and technology roadmap. J. Phys. D-Appl. Phys. 2017, 50, 043001. [CrossRef]

20. Engelbrecht, S.; Tybussek, K.H.; Fischer, B.; Sommer, S. THz-TDS on polymers: Monitoring thermo-oxidative ageing and crystallization kinetics. In Proceedings of the 2018 43rd International Conference on Infrared, Millimeter and Terahertz Waves (IRMMW-THz), Nagoya, Japan, 9-14 September 2018; pp. 1-2.

21. Scheller, M. Data Extraction from Terahertz Time Domain Spectroscopy Measurements. J. Infrared Millim. Terahertz Waves 2014, 35, 638-648. [CrossRef]

22. Smith, R.M.; Arnold, M.A. Terahertz Time-Domain Spectroscopy of Solid Samples: Principles, Applications, and Challenges. Appl. Spectrosc. Rev. 2011, 46, 636-679. [CrossRef]

23. Synkiewicz-Musialska, B.; Szwagierczak, D.; Kulawik, J.; Palka, N.; Piasecki, P. Structural, Thermal and Dielectric Properties of Low Dielectric Permittivity Cordierite-Mullite-Glass Substrates at Terahertz Frequencies. Materials 2021, 14, 4030. [CrossRef] [PubMed]

24. Peters, O.; Schwerdtfeger, M.; Wietzke, S.; Sostmann, S.; Scheunemann, R.; Wilk, R.; Holzwarth, R.; Koch, M.; Fischer, B.M. Terahertz spectroscopy for rubber production testing. Polym. Test 2013, 32, 932-936. [CrossRef]

25. Wietzke, S.; Jansen, C.; Reuter, M.; Jung, T.; Kraft, D.; Chatterjee, S.; Fischer, B.M.; Koch, M. Terahertz spectroscopy on polymers: A review of morphological studies. J. Mol. Struct. 2011, 1006, 41-51. [CrossRef]

26. Lian, Z.; Min, D.; Li, S.; Han, Y. New Insight Into the Molecular Dynamics of Epoxy/Aluminum Hydroxide Nanocomposites by Terahertz Time-Domain Spectroscopy. IEEE Trans. Terahertz Sci. Technol. 2019, 9, 383-391. [CrossRef]

27. Singh, K.; Bandyopadhyay, A.; Sengupta, A. Physics of effective media in plastic polymer-composites using THz Time-Domain Spectroscopy. J. Phys. D-Appl. Phys. 2022, 55. [CrossRef]

28. Przewłoka, A.; Smirnov, S.; Nefedova, I.; Krajewska, A.; Nefedov, I.S.; Demchenko, P.S.; Zykov, D.V.; Chebotarev, V.S.; But, D.B.; Stelmaszczyk, K.; et al. Characterization of Silver Nanowire Layers in the Terahertz Frequency Range. Materials 2021, 14, 7399. [CrossRef]

29. Gorokhov, G.; Bychanok, D.; Gayduchenko, I.; Rogov, Y.; Zhukova, E.; Zhukov, S.; Kadyrov, L.; Fedorov, G.; Ivanov, E.; Kotsilkova, R.; et al. THz Spectroscopy as a Versatile Tool for Filler Distribution Diagnostics in Polymer Nanocomposites. Polymers 2020, 12, 3037. [CrossRef]

30. Fandio, D.J.J.; Sauze, S.; Boucherif, A.; Ares, R.; Morris, D. Structural, optical and terahertz properties of graphene-mesoporous silicon nanocomposites. Nanoscale Adv. 2020, 2, 340-346. [CrossRef] 
31. Wang, S.; Yu, S.; Li, J.; Li, S. Effects of Functionalized Nano-TiO2 on the Molecular Motion in Epoxy Resin-Based Nanocomposites. Materials 2020, 13, 163. [CrossRef] [PubMed]

32. McMaster, M.S.; Yilmaz, T.E.; Patel, A.; Maiorana, A.; Manas-Zloczower, I.; Gross, R.; Singer, K.D. Dielectric Properties of Bio-Based Diphenolate Ester Epoxies. ACS Appl. Mater. Interfaces 2018, 10, 13924-13930. [CrossRef] [PubMed]

33. Mohan, P. A Critical Review: The Modification, Properties, and Applications of Epoxy Resins. Polym.-Plast. Technol. Eng. 2013, 52, 107-125. [CrossRef]

34. Kourkoutsaki, T.; Logakis, E.; Kroutilova, I.; Matejka, L.; Nedbal, J.; Pissis, P. Polymer Dynamics in Rubbery Epoxy Networks /Polyhedral Oligomeric Silsesquioxanes Nanocomposites. J. Appl. Polym. Sci. 2009, 113, 2569-2582. [CrossRef]

35. Katayama, J.; Ohki, Y.; Fuse, N.; Kozako, M.; Tanaka, T. Effects of Nanofiller Materials on the Dielectric Properties of Epoxy Nanocomposites. IEEE Trans. Dielectr. Electr. Insul. 2013, 20, 157-165. [CrossRef]

36. Ferguson, B.; Zhang, X.C. Materials for terahertz science and technology. Nat. Mater. 2002, 1, 26-33. [CrossRef] [PubMed]

37. Withayachumnankul, W.; Naftaly, M. Fundamentals of Measurement in Terahertz Time-Domain Spectroscopy. J. Infrared Millim. Terahertz Waves 2014, 35, 610-637. [CrossRef]

38. Duvillaret, L.; Garet, F.; Coutaz, J.-L. Highly precise determination of optical constants and sample thickness in terahertz time-domain spectroscopy. Appl. Opt. 1999, 38, 409-415. [CrossRef]

39. Dorney, T.D.; Baraniuk, R.G.; Mittleman, D.M. Material parameter estimation with terahertz time-domain spectroscopy. J. Opt. Soc. Am. A-Opt. Image Sci. Vis. 2001, 18, 1562-1571. [CrossRef] [PubMed]

40. D'Angelo, F.; Mics, Z.; Bonn, M.; Turchinovich, D. Ultra-broadband THz time-domain spectroscopy of common polymers using THz air photonics. Opt. Express 2014, 22, 12475-12485. [CrossRef]

41. Oughstun, K.E.; Cartwright, N.A. On the Lorentz-Lorenz formula and the Lorentz model of dielectric dispersion. Opt. Express 2003, 11, 1541-1546. [CrossRef] 